survival in elderly patients but enormously enhances the quality of remaining life. How often hypopituitarism is responsible for postural hypotension is unclear, but pointers seen in our patients included low serum thyroxine concentrations without the expected raised thyroid stimulating hormone, hyponatraemia, and disproportionately pale facies.

I am grateful to Dr R J Machell, Penzance, Dr J E Earis, Liverpool, Dr N G Dey, Southport, Dr J Playfer, Liverpool and Dr G Phillips, Liverpool, for permission to report on these patients.

1 Green MF. Geriatric endocrinology. In: Keynes WM and Fowler PBS, eds. Tutorials in postgraduate medicine. Clinical endocrinology. London: William

2 Saeger $W$. Pathology of the pituitary gland. In: Belchetz PE, ed. Management of

3 Daniel PM, Treip CS. The pathology of the hypothalamus. Clin Endocrinol Metab 1977;6:3-19.

4 Sheehan HL, Davis JC. Post-partum hypopituitarism. Springfield: Charles C
Thomas, 1982 .

Accepted 19 February 1985)

Department of Medicine, University of Liverpool, PO Box 147, Liverpool L69 3BX

P E BELCHETZ, MD, FRCP, senior lecturer in medicine

\section{Visual evoked potential and contrast sensitivity function in diabetic retinopathy}

Retinopathy is a major complication of diabetes, but clinically obvious optic neuropathy is uncommon. Recent reports of abnormal visual evoked potentials in diabetics without retinopathy have been conflicting. ${ }^{12}$ We therefore studied the function of the visual pathway using the visual evoked potential and contrast sensitivity function in diabetics with and without retinopathy. In the absence of ocular disease a delayed visual evoked potential indicates abnormal transmission of nerve impulses from the retina to the visual cortex. The contrast sensitivity function is a psychophysical method of detecting subtle disturbances of the visual system such as early glaucoma and lesions of the optic nerve. ${ }^{34}$

\section{Subjects, methods, and results}

We studied 22 insulin dependent diabetics aged 20-35, of whom five did not have retinopathy, 11 had background retinopathy, and six had proliferative retinopathy. The table shows the clinical details. The three groups were comparable for age and glycosylated haemoglobin concentration. All patients had a corrected visual acuity of $6 / 9$ and J6 or better.

The visual evoked potential was recorded using a standard technique. In each patient 128 responses were averaged and the latency of the major positive peak calculated. The contrast sensitivity function was determined using a standard method based on previous work. ${ }^{4}$ All testing was performed uniocularly. Reference values for both tests were obtained in non-diabetic controls matched for age and sex, and results were considered to be abnormal if they exceeded the mean $+2 \mathrm{SD}$ in the control group. Statistical analysis was by the permutation $t$ test.

All patients with proliferative retinopathy showed delayed visual evoked potentials, compared with only one patient without retinopathy $(p<0.001)$ and five with background retinopathy $(\mathrm{p}<0.01)$ (table). There was no significant difference, however, between the group with background retinopathy and the group without retinopathy. There were no differences between any of the groups in the prevalence of abnormal contrast sensitivity.

\section{Comment}

Although clinically manifest optic neuropathy is uncommon in diabetes, subclinical disease might be relatively common. Our findings show that in the absence of retinopathy there is no significant increase in the proportion of diabetic patients with either an abnormal visual evoked potential or abnormal contrast sensitivity function. Although ${ }_{c}$ the range of severity of background retinopathy was wide, this was likewise not associated with abnormalities in these tests. There was, however, a strong correlation between prolifertive retinopathy and an abnormal evoked potential.

Neuronal degeneration in the ganglion cell and layers of nerve $\$$ fibre is one of the earliest changes in diabetic retinopathy, ${ }^{5}$ and presumably patients with proliferative changes have more extensive.neuronal and vascular retinal damage than those with background $\overrightarrow{\vec{*}}$ retinopathy. Our findings could reflect either damage to the maculo-? papillary fibres in the retina or subclinical optic neuropathy. Ouro observations are unlikely to have been related to coagulation treatment $\underline{\underline{ }}$. with argon laser light as none of the patients had undergone this treat- $\frac{\bar{p}}{-}$. ment within six months of testing. None had received retrobulbar $\stackrel{\mathbb{Q}}{\mathcal{O}}$ anaesthesia or sustained vitreous haemorrhages.

These results do not agree with the previous findings of abnormal visual evoked potentials in patients without clinical diabetic retino- $\overrightarrow{0}$ pathy ${ }^{1}$ and abnormalities of contrast sensitivity in patients with minimal retinopathy. ${ }^{3}$ Our findings imply subclinical neuronal damage in $\vec{\omega}$

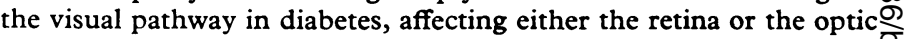
nerve. This seems, however, to be a feature only of patients with proliferative retinopathy.

We thank Miss Joan Lennie for preparing the manuscript, Dr R J Prescott. for statistical advice, and Dr E H Jellinek and Dr B Ashworth for their helpful comments.

1 Puvanendron K, Devathasan G, Wong PK. Visual evoked response in diabetes.

I Neurol Neurosurg Psychiatry 1983;46:43-7.
Cirillo D, Gonfiantini E, De Grandis D, et al. Visual evoked responses in diabetic 1 d

children and adolescents. Diabetes Care 1984;7:273-5.
Arden GB. Visual loss in patients with normal visual acuity. Trans Ophthalmol음 Soc UK 1976;96:372-6.

mmern RL, Campbell FW, Wilkinson IMS. Subtle disturbances of vision after $N$ optic neuritis elicited by studying contrast sensitivity. I Neurol Neurosurg Bloodworth JMB. Diabetic retinopathy. Diabetes 1962;11:1-22.

(Accepted 29 April 1985)

University of Edinburgh, Department of Medical Neurology

Northern General Hospital, Edinburgh EH5 2DQ

A COLLIER, MB, MRCP, registrar

J D MITCHELL, MB, MRCP, temporary senior lecturer

Diabetic and Dietetic Department, Royal Infirmary, Edinburgh EH3 9YW

B F CLARKE, MB, FRCP, consultant physician

Correspondence to: Dr Mitchell.

\section{Effect of inhalation of corticosteroids on exercise induced asthma: randomised double blind crossover study of budesonide in asthmatic children}

Corticosteroids are well established in the management of bronchial asthma and are thought to act by inhibiting the late asthmatic reaction. Whether they have any effect on immediate reactions like exercise induced asthma is controversial. Generally, they are thought to be $\omega$ ineffective in exercise induced asthma, whether given short or long $O$ term and orally or by inhalation, ${ }^{12}$ but attenuation of exercise inducedo asthma has been shown during regular treatment with inhaled steroids.$^{34} \mathrm{I}$ report the results of a double blind placebo controlled $\stackrel{S}{+}$ study in which children with exercise induced asthma received budesonide acrosol for three weeks.

Clinical details of patients and results of tests of visual function

\begin{tabular}{|c|c|c|c|c|c|c|c|}
\hline Retinopathy & No of patients & Mean (SD) age (years) & $\begin{array}{l}\text { Mean (SD) duration } \\
\text { of diabetes (years) }\end{array}$ & $\begin{array}{c}\text { Mean (SD) } \\
\text { glycosylated } \\
\text { haemoglobin }(\%)\end{array}$ & No of eyes tested & $\begin{array}{l}\text { No with abnormal } \\
\text { visual evoked } \\
\text { potential }\end{array}$ & $\begin{array}{l}\text { No with abnormal } \\
\text { contrast sensitivity } \\
\text { function }\end{array}$ \\
\hline $\begin{array}{l}\text { None } \\
\text { Background } \\
\text { Proliferative }\end{array}$ & $\begin{array}{r}5(4 M, 1 F) \\
11(6 M, 5 F) \\
6(4 M, 2 F)\end{array}$ & $\begin{array}{l}25 \cdot 4(3 \cdot 9) \\
27.9(2 \cdot 8) \\
27 \cdot 8(5 \cdot 0)\end{array}$ & $\begin{array}{r}8 \cdot 8(1 \cdot 0) \\
15 \cdot 0(4 \cdot 1) \\
15 \cdot 2(4 \cdot 4)\end{array}$ & $\begin{array}{l}10.8(1.8) \\
10.5(1.5) \\
12.5(2.5)\end{array}$ & $\begin{array}{l}10 \\
22 \\
12\end{array}$ & $\begin{array}{r}1 \\
5 \\
12\end{array}$ & $\cdot$ \\
\hline
\end{tabular}




\section{Patients, methods, and results}

Sixteen children aged 8 to 15 (mean 10.9 ) years with perennial asthma were selected on the basis of $>20 \%$ decrease in lung function after exercise. None had received corticosteroids within the past three months. Sodium cromoglycate was stopped 24 hours before the study and inhaled $B_{2}$ agonists eight hours before visits.

The study consisted of two three week treatment periods separated by a fortnight's wash out; during each treatment period participants received $200 \mu \mathrm{g}$ budesonide aerosol twice daily through a $750 \mathrm{ml}$ cone spacer or a placebo with a double blind randomised crossover protocol. Immediately before and at the end of each treatment period the children performed an exercise test and delivered a 24 hour urinary sample for analysis of cortisol. The exercise challenge consisted of five or six minutes of continuous running on a treadmill at individually adjusted, submaximal workloads. Heart rate was measured by radiotelemetry, and all subjects wore a nose clip during exercise. The absolute humidity was recorded.

Forced expiratory volume in one second was recorded on a dry spirometer (Vitalograph) before exercise (baseline) and three or five, 10, and 20 minutes after exercise. Results were expressed as the maximal percentage fall from the baseline value. Urinary cortisol was measured by radioimmunoassay. Two

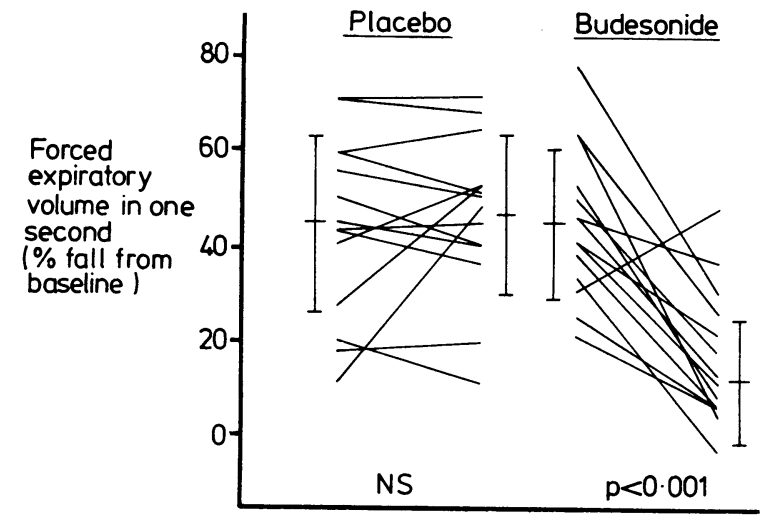

Individual percentage falls in forced expiratory volume in one second induced by exercise before and after three weeks' treatment with budesonide aerosol and its placebo. Means (SD) are shown. inhaled steroids may be valuable in managing troublesome exercise induced asthma.

I thank Anders Holst Andersen for statistical help and A B Draco (Sweden) for the budesonide, placebo medihalers, and cone spacers.

König P, Jaffe P, Godfrey S. Effects of corticosteroids on exercise-induced asthma.

7 Allergy Clin Immunol 1974;54:14-9.
Smith J. Inhaled steroids in the management of childhood asthma. In: Clark TJH ed. Steroids in asthma. Auckland: Adis Press, 1983.

Hartley JPR, Charles TJ, Seaton A. Betamethasone valerate inhalation and exercise-induced asthma in adults. Br $\mathcal{F}$ Dis Chest 1977;71:253-8.

4 Henriksen JM, Dahl R. Effects of inhaled budesonide alone and in combination with low-dose terbutaline in children with exercise-induced asthma. Am Rev Respir Dis 1983;128:993-7.

5 Martin GL, Atkins PC, Dunsky EH, Zweiman B. Effect of theophylline, terbutaline and prednisone on antigen-induced bronchospasm and mediator release. $\mathcal{J}$ Allergy Clin Immunol 1980;66:204-12.

(Accepted 2 May 1985)

Pediatric Department, University Hospital, Aarhus, Denmark

JØRN M HENRIKSEN, MD, registrar in paediatrics

Correspondence to: Dr Henriksen, Pediatric Department, Aarhus Kommunehospital, 8000 Aarhus C, Denmark.

\section{Fatal exacerbation of systemic lupus erythematosus after treatment with griseofulvin}

Most cases of systemic lupus erythematosus pursue a chronic relapsing course. Some drugs that are commonly prescribed and considered to be fairly safe can exacerbate existing disease, unmask a lupus diathesis, or produce a drug induced lupus syndrome. Awareness that drugs can adversely alter the course of systemic lupus erythematosus could prevent morbidity and death. We report a fatal exacerbation of systemic lupus erythematosus presumed to be due to griseofulvin.

\section{Case report}

way analysis of varian
level) were performed.

Fourteen children completed the study. Mean (SD) baseline forced expiratory volume in one second ( $\%$ predicted) improved from $84(17) \%$ to 94 $(16) \%(p<0.02)$ during treatment; placebo showed no effect. Budesonide reduced the mean fall in forced expiratory volume in one second from 45 $(16) \%$ to $17(14) \%(\mathrm{p}<0.001)$ (figure). No carryover effect from the treatment was detected after wash out. No significant changes occurred in the test conditions (absolute humidity, final heart rate, and workload). The mean 24 hour urinary free cortisol excretion was $94(55) \mathrm{nmol} / \mathrm{l}(3.4(2 \cdot 0) \mu \mathrm{g} / 100 \mathrm{ml})$ and $116(55) \mathrm{nmol} / \mathrm{l}(4 \cdot 2(2 \cdot 0) \mu \mathrm{g} / 100 \mathrm{ml})$ before treatment and $96(34) \mathrm{nmol} / \mathrm{l}$ $(3.5(1 \cdot 2) \mu \mathrm{g} / 100 \mathrm{ml})$ and $85(34) \mathrm{nmol} / 1(3 \cdot 1(1 \cdot 2) \mu \mathrm{g} / 100 \mathrm{ml})$ after placebo and budesonide, respectively $(\mathrm{F}=1.64$; df $3.44, \mathrm{NS})$. One case of hoarseness during budesonide treatment was the only side effect reported.

\section{Comment}

Budesonide given by inhalation for three weeks afforded significant protection against exercise induced asthma in most children without appreciable suppression of adrenal function. Improvement in baseline airway function cannot explain the effect of budesonide on exercise induced asthma. ${ }^{4}$ Normal 24 hour urinary free cortisol excretion cannot exclude more subtle degrees of adrenal suppression.

The present results and the finding that the immediate reaction induced by allergen was blocked after a week's treatment with prednisone $^{5}$ show that regular steroid treatment attenuates some immediate asthmatic reactions. The pathogenesis of exercise induced asthma and the precise modes of action of steroids, however, are incompletely understood. It is generally accepted that the airway cooling that occurs during exercise initiates the bronchoconstriction, but the mechanism is unknown. The decrease in bronchial reactivity during steroid treatment might result from decreased mucosal inflammation, reflex activity, or mediator release.

Inhaled $\mathrm{B}_{2}$ agonists are the most effective drugs against exercise induced asthma, though the duration of action of bronchodilators is short and the effect sometimes insufficient, especially in severe cases. Additionally, children often forget to use or refrain from using prophylactic medicine when necessary. The present results suggest
A 22 year old woman with a six year history of systemic lupus erythematosus was admitted after one month of malaise, sweating, and fever. The diagnosi had initially been made on the basis of fever, lymphadenopathy, Raynaud's phenomenon, digital vasculitis, photosensitivity, and butterfly rash. Antinuclear and native double stranded deoxyribonucleic acid (DNA) antibodies were present in considerable but varying titres. She subsequently developed proteinuria. Renal biopsy showed focal proliferative glomerulonephritis cerebral lupus was presumed to be present because of changes in personality and an electroencephelogram showed diffuse slow wave activity. She was given maintenance treatment of prednisolone $7 \mathrm{mg}$ on alternate days.

Over the month before admission her generai practitioner had prescribed ampicillin and erythromicin for a presumed respiratory tract infection. Griseofulvin had been prescribed seven days before admission; although the precise amount was unknown, the total dose could not have exceeded : $g$

On admission she looked unwell and had a fever of $38.7^{\circ} \mathrm{C}$, pulse rate 110 beats/min regular, and blood pressure (supine) $120 / 100 \mathrm{~mm} \mathrm{Hg}$. Results of examination were otherwise normal with no cutaneous signs of systemic lupus erythematosus and no obvious source of sepsis. White cell count was $3.9 \times 10^{9} / 1$, haemoglobin concentration $10.5 \mathrm{~g} / \mathrm{dl}$, and erythrocyte sedimentation rate $121 \mathrm{~mm}$ in the first hour; $C$ reactive protein was absent, and blood, electrolyte concentrations, and results of a shor $i$ Synacthen test were normal Liver enzyme activity (aspartate transaminase, alanine transaminase, and $\gamma$ glutamyl transferase) and bilirubin concentrations were normal, as was a chest $x$ ray film. DNA binding was $41 \%$ (normal $<30 \%$ ). She was presumed to have an exacerbation of her disease rather than infection, and prednisolone was increased.

On the second day in hospital she developed symptoms of a peripheral, sensory polyneuropathy and left lateral popliteal nerve palsy. Examination of cerebrospinal fluid showed a normal cell count and protein concentration. Results of gram staining and culture were negative. An intravenous bolus of methylprednisolone $1 \mathrm{~g}$ was given with symptomatic benefit. Further neurological signs did not develop, but nausea and a low intake of fluid necessitated intravenous fluids.

On the fourth day a further $1 \mathrm{~g}$ methylprednisolone was given for weakness Objective and biochemical evidence of myositis was absent. Urea and creatinine concentrations had risen to $16 \mathrm{mmol} / 1(96 \mathrm{mg} / 100 \mathrm{ml}$ ) (normal $2 \cdot 5-8.0 \mathrm{mmol} / \mathrm{l}(15-48 \mathrm{mg} / 100 \mathrm{ml})$ ) and $180 \mu \mathrm{mol} / 1(2.0 \mathrm{mg} / 100 \mathrm{ml})$ (normal 40-130 $\mu \mathrm{mol} / 1(0 \cdot 5-1 \cdot 5 \mathrm{mg} / 100 \mathrm{ml})$ ) respectively. Intravenous fluids were increased to maintain a positive fluid balance. sputum, and urine cultures yielded negative results. Renal function 